\title{
Positron Accumulator Ring (PAR) Power Supply
}

\author{
by: Masoud Fathizadeh
}

\section{Introduction}

The Positron Accumulator Ring (PAR) consists of 8 dipole magnets connected in series. These magnets are energized via one 12-pulse dc power supply. Figure 1 shows the block diagram for the power supply.

The power supply consists of four phase controlled half-wave wye group converters. Each of the two half-wave converters are connected through an interphase transformer to obtain a fullwave converter with $120^{\circ}$ conduction. The input voltage for these two half-wave converters are $180^{\circ}$ apart. The two full-wave converters are connected in parallel through a third interphase transformer. This type of connection of the converters not only provides the required output current, it also improves the input power factor of the power supply. The output of the wye group converters is filtered through a passive L-R-C filter to reduce the ripple content of the output current. At low current values of the power supply the current ripple is high, thus a large filter is needed, which adds to the cost of the power supply, however at high output current levels, the current ripple is less severe. The large size of the filter can be reduced by adding an anti-parallel rectifier diode(D1) to the output of the power supply. A freewheeling diode(D2) is connected before the choke to circulate the current once the power supply is turned off. In order to measure the current in the magnet a high precision, low drift, zero flux current transductor is used. This transductor senses the magnet current which provides a feedback signal to control the gating of the converter's thyristors. A true 14 bit Digital to Analog Converter (DAC) is programmed by the control computer for the required current value, providing a reference for the current regulator. Fast correction of the line transients is provided by a relatively fast voltage loop controlled by a high gain slow response current loop. Diodes D1 and D2 along with the current and voltage loops are shown in Figure 1. 


\section{DISCLAIMER}

This report was prepared as an account of work sponsored by an agency of the United States Government. Neither the United States Government nor any agency thereof, nor any of their employees, makes any warranty, express or implied, or assumes any legal liability or responsibility for the accuracy, completeness, or usefulness of any information, apparatus, product, or process disclosed, or represents that its use would not infringe privately owned rights. Reference herein to any specific commercial product, process, or service by trade name, trademark, manufacturer, or otherwise does not necessarily constitute or imply its endorsement, recommendation, or favoring by the United States Government or any agency thereof. The views and opinions of authors expressed herein do not necessarily state or reflect those of the United States Government or any agency thereof. 


\section{DISCLAIMER}

Portions of this document may be illegible in electronic image products. Images are produced from the best available original document. 
3

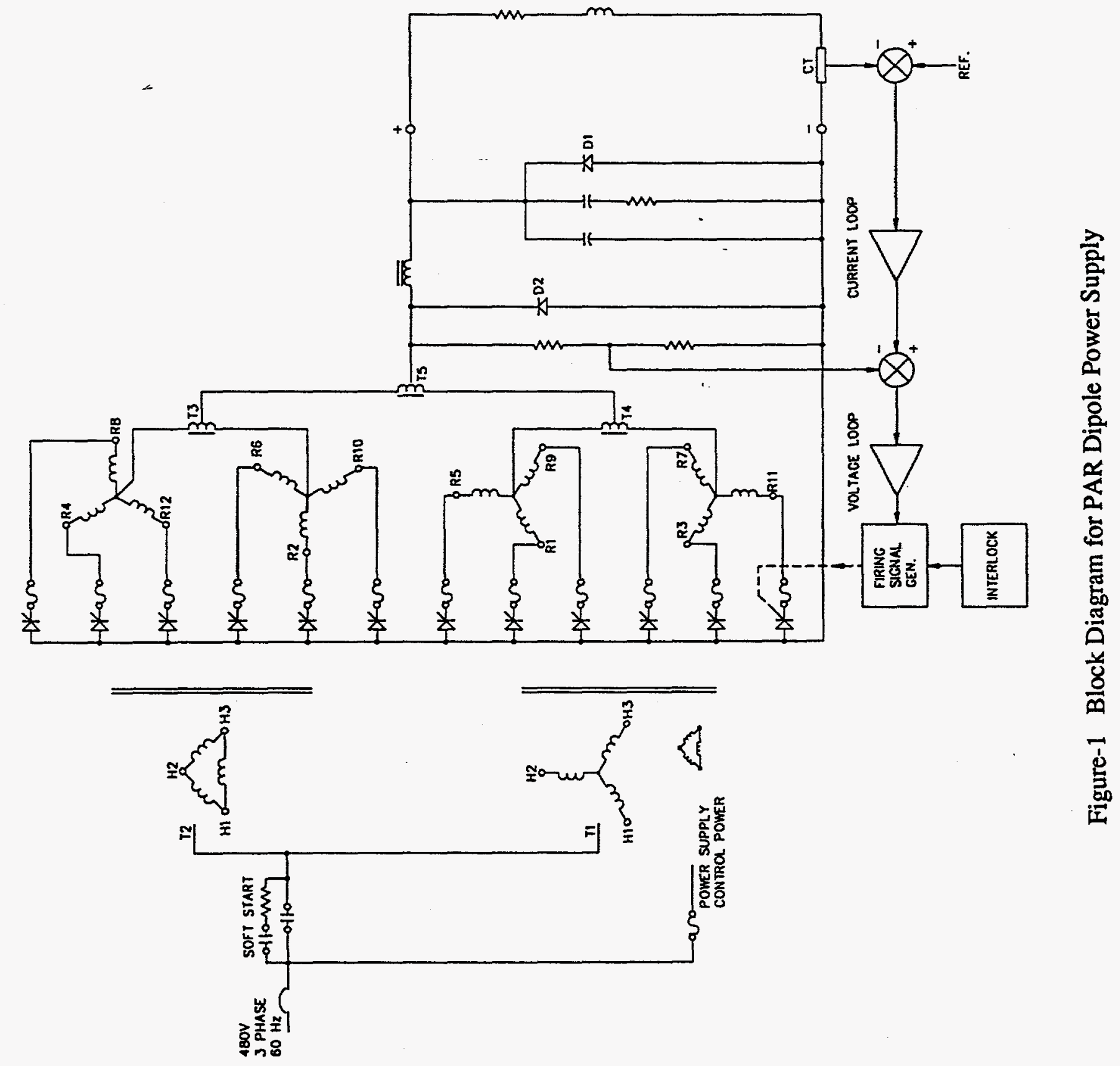




\section{Circuit Rating}

The circuit rating of the PAR dipole power supply is given in the following [1]:

Number of power supply

1

Current [A]

420

Number of Magnets

8

Total Resistance of Magnets [ $\Omega$ ]

0.72

Total Inductance of Magnets [H]

0.848

Voltage Rating [V]

335

$P_{\text {rated }}[\mathrm{kW}]$

141

Input Voltage [V]

$480 \pm 10 \%$

Input Frequency [Hz]

$60 \pm 0.2$

Input Voltage Unbalance $3 \%$

Available Short Circuit Current [kA] 30

Maximum Ambient Temperature $\left[{ }^{\circ} \mathrm{C}\right]$

50

Minimum Ambient Temperature $\left[{ }^{\circ} \mathrm{C}\right]$

10

Cooling Water Temperature $\left[{ }^{\circ} \mathrm{F}\right]$

$90 \pm 10$

Conductivity $[\mu-\mathrm{mho} / \mathrm{cm}]$

5

Maximum Inlet Pressure [psi]

200

Differential Pressure [psi] 70

Maximum Pressure that P.S. Withstand [psi] 250

Cooling Water Requirement [gpm] 5

Regulation $\Delta \mathrm{U} / \mathrm{I}_{\max }$

Stability

Reproducibility

$\pm 1 \times 10^{-4}$

Current Ripple

$\pm 2 \times 10^{-4}$

Tracking Error

$\pm 3 \times 10^{-4}$

Resolution of Reference [bits]

$\pm 5 \times 10^{-4}$

14

\section{Design and Analysis}

The calculations needed for the design of PAR dipole power supply consist of five parts, these parts are as follows:

3.1) Power Section and Cooling Requirement 
3.2) Control Scheme

3.3) Calculation of Power Supply Rating

3.4) Interlocks

3.5) Modelling, Computer Simulation and Analysis of Results

In the following each of the above sections will be discussed in details.

\subsection{Power Section and Cooling Requirement}

In this section the transformer, thyristors, interphase transformers, and filter will be discussed. The voltage, current and power rating along with the cooling requiremnets for each component will be calculated.

\subsubsection{Transformer Design Requirement}

Two three phase transformers are used in the power supply. One transformer has a delta connected primary with two sets of wye connected secondary windings. However, the other transformer has a wye connected primary with two wye connected secondaries. A delta connected tertiary windings is also provided to eliminate the zero sequence current. Three interphase transformers are used to connect the outputs of the converters in parallel. Figure 1 clearly shows the connection of these interphase transformers. The phasor diagram for voltages at the secondary windings of the transformers is given in Figure 2.

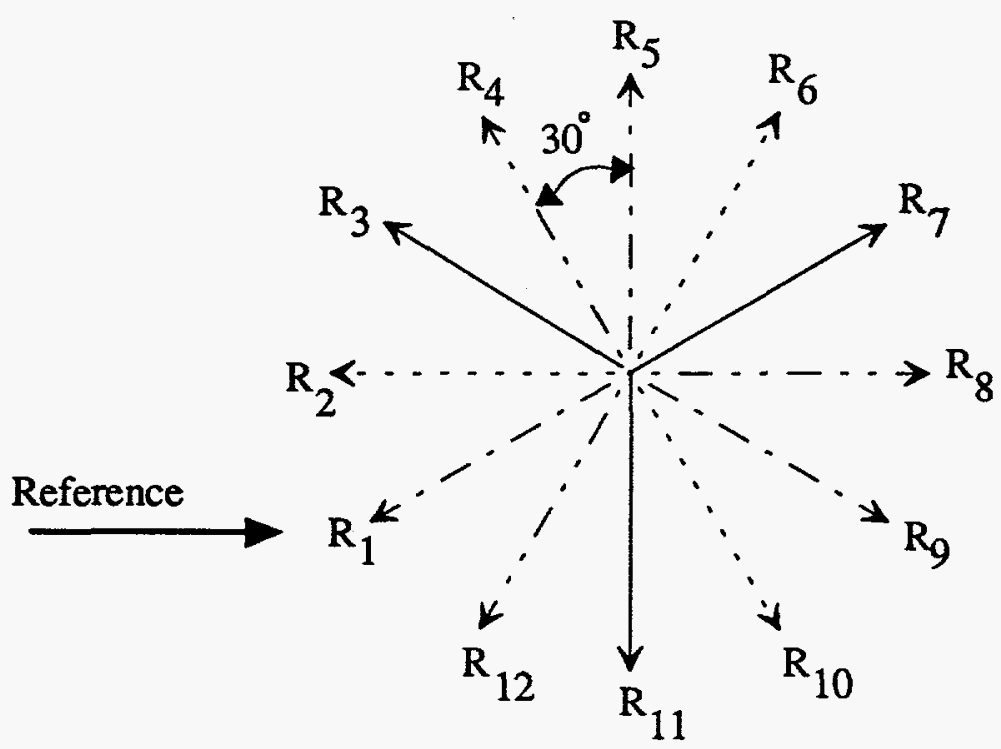

Figure-2 Voltage Phasor Diagram at Secondary Windings of Transformers 
In order to provide the current and voltage necessary to operate the magnet; the following parameters for each transformer are specified.

Input Voltage:

Secondary Line to Line Voltage:

Apparent Power:

Input Current:

Impedance:

Transformer Temperature Rise

Cooling Water Required

Line Voltage Imbalanace
$480 \mathrm{Vac} @ 60 \mathrm{~Hz}$

$430 \mathrm{~V}$

92 kVA @ efficiency of $85 \%^{*}$

$110 \mathrm{~A}$

$5 \%$ on per unit base

$17^{\circ} \mathrm{C}$

$1.92 \mathrm{gpm}$

$\pm 3 \%$

* The efficiency of the transformer must be higher than $85 \%$, however this value is used to calculate the cooling water requirement.

\subsubsection{Thyristor Rating}

The average current rating of each thyristor is $100 \mathrm{~A}$ with on-state voltage of $2.5 \mathrm{~V}$. The peak reverse blocking $1000 \mathrm{~V}$. Each device is expected to have $8^{\circ} \mathrm{C}$ temperature rise.

\subsubsection{Interphase Transformers}

In order to connect two half-wave converters in parallel, an interphase transformer is used. The interphase transformer allows two of the half-wave converters connected in parallel to conduct for the maximum of a $120^{\circ}$ conduction angle and share the load current. This interphase transformer basically consists of a core and a coil with a center tap. When the two half-wave converters are contributing equal amounts of voltage, the interphase transformer is transparent, but when the output voltage of the half-wave converters are not equal, the windings of the interphase transformer show enough impedance to support the voltage imbalance. Each leg of the interphase transformer is assumed to have $10 \mathrm{mH}$ inductance and $10 \mathrm{~m} \Omega$ resistance. This amount of inductance is sufficient to support $20 \%$ voltage mismatch across the interphase transformer. The current produced due to the $20 \%$ voltage mismatch should not saturate the core of the interphase transformer.

\subsubsection{Filter Design}

The basic ripple frequency of the power supply is $720 \mathrm{~Hz}$. However, due to imbalance in the transformers, ripple with frequencies lower than $720 \mathrm{~Hz}$ can appear in the power supply output. 
A filter with very low cut-off frequency can eliminate all ripple frequencies. However, such a filter will render a high cost power supply with a relatively slow time response. Therefore a filter with a cut-off frequency of $65 \mathrm{~Hz}$ is designed to eliminate all ripple frequencies above 60 Hz. The circuit diagram for such a filter is given in Figure 3. The filter consists of an inductance, two capacitor banks, and a damping resistor. The damping resistor is in series with one of the capacitor banks to reduce the heat loss in the filter. The transfer function of such a filter is given in the following [2].

$$
\frac{e_{o}}{e_{i}}=\frac{\left(s T_{2}+1\right)}{s^{3} T_{2} L_{1} C_{1}+S^{2}\left(T_{1} T_{2}+L_{1} C_{2}\right)+s\left(T_{1}+T_{2}+T_{3}\right)+1}
$$

where $T_{1}=R_{1} C_{1}, T_{2}=R_{2} C_{2}$ and $T_{3}=R_{1} C_{2}$

The filter is designed with parameter values of $\mathrm{L}_{1}=500 \mu \mathrm{H}, \mathrm{C}_{1}=5913 \mu \mathrm{F}, \mathrm{C}_{2}=11825 \mu \mathrm{F}$, and $R_{2}=412 \mathrm{~m} \Omega$. The Bode plots for the magnitude and phase response of the filter is given in Figures 4 and 5 respectively.

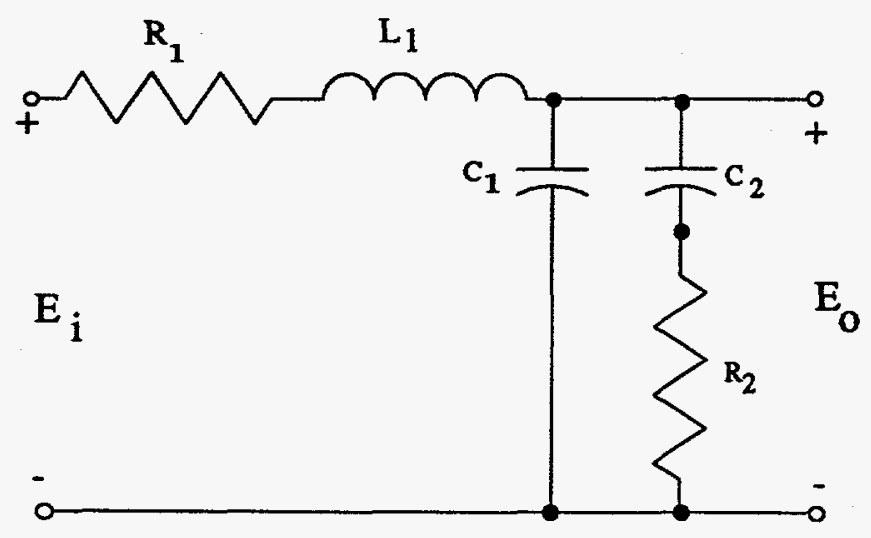

Figure-3 Low Pass Filter for PAR Dipole Power Supply 


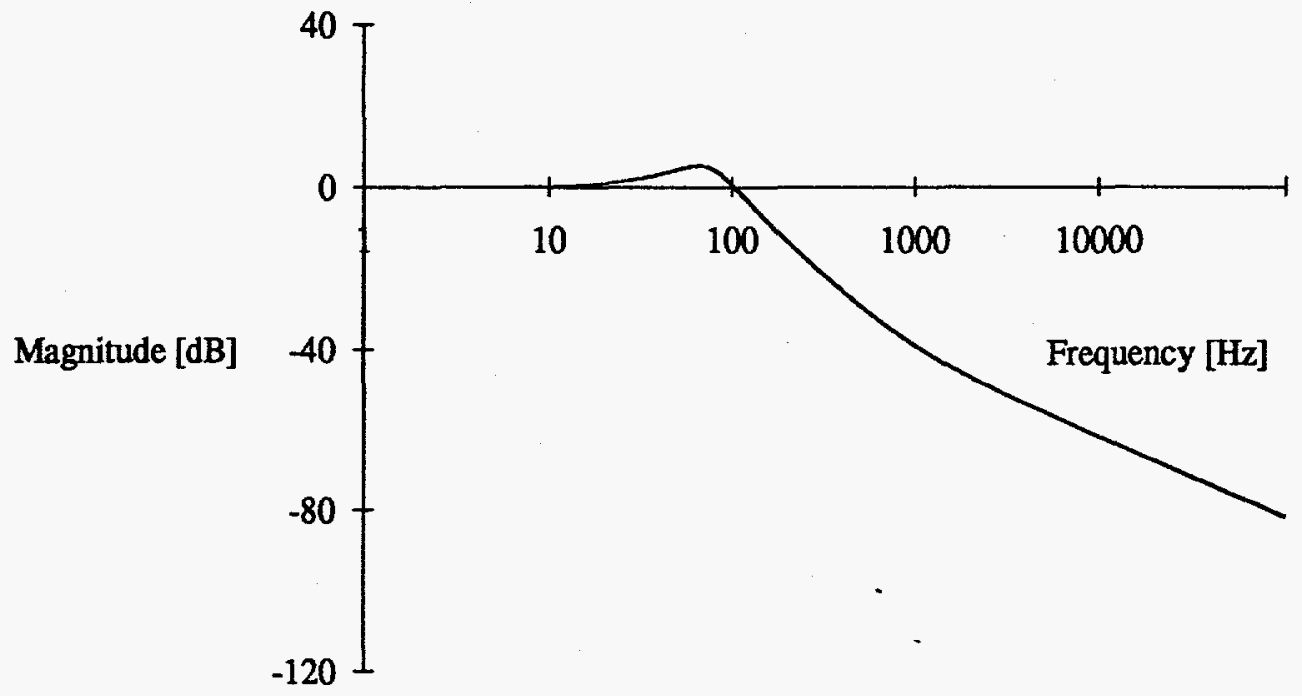

Figure-4 Magnitude Response for Power Supply Main Filter

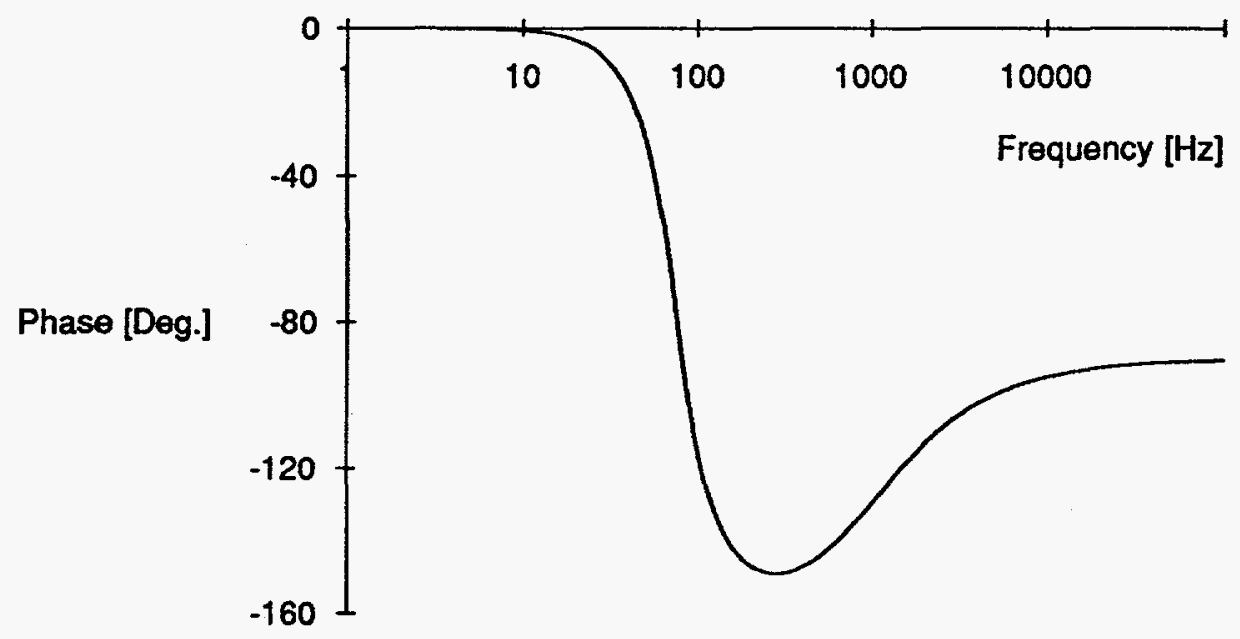

Figure-5 Phase Response for Power Supply Main Filter 


\subsection{Control Scheme}

Two control loops are utilized to regulate the current in the magnet chain. These loops consist of a slow response, high gain current loop and a fast response voltage loop. A high precision, low drift, zero flux current transductor is used to sense the current in the magnet chain. A true 14 bit DAC which is programmed by the control computer for the required current level, provides the reference for the current regulator. The difference between the current reference and the current transductor output is fed to a high precision, proportional plus integral (PI) controller. This controller provides the controlling signal for the thyristor firing circuit, and subsequently the firing circuit provides triggering pulses to the thyristors in the converters.

\subsubsection{Controller}

In order to regulate the magnet current, a proportional control is usually needed. However, this control scheme always requires a small input signal to operate, which results in an offset between the magnet current and the reference. This problem can be somewhat resolved by increasing the proportional gain of the controller, but high proportional gain may result in an oscillation which is undesirable. A better approach to the problem of providing a controller with a zero offset is to introduce an integrator to the controller, which will eliminate the offset current. For the fast response voltage loop and high gain current loops, proportional plus integral controllers were used. The block diagram for the suggested control circuit along with the firing circuit is given in Figure 6. The voltage and current loop time responses must be set correctly in order to obtain a proper control of the current in the magnet load. Thus, the voltage loop controller response time is set to correct for $720 \mathrm{~Hz}$ ripple, while the current loop controller response time is set equal to the response time of the load magnet.

\subsubsection{Firing Circuit}

The firing signal generator consists of a blanking logic, ramp generator, comparator, amplifier and pulse transformers. A precision ramp generator generates a chain of linear and equal ramp waveforms. The blanking logic circuit generates a sequence of 12 pulses per line cycle. These pulses are used to produce a sequence of twelve ramp signals via ramp generator circuits. Only one of the pulses in the blanking logic circuit is synchronized with the line, the remaining eleven pulses are generated through an electronic time delay circuit. A comparator is used to compare the ramp signal with the reference signal, given by the current and voltage controllers, which produces firing pulses for the thyristors. These pulses are amplified to obtain sufficient current to drive the 12 thyristors in the converters. The trigger pulses are fed to the gates of the thyristors via pulse transformers. 

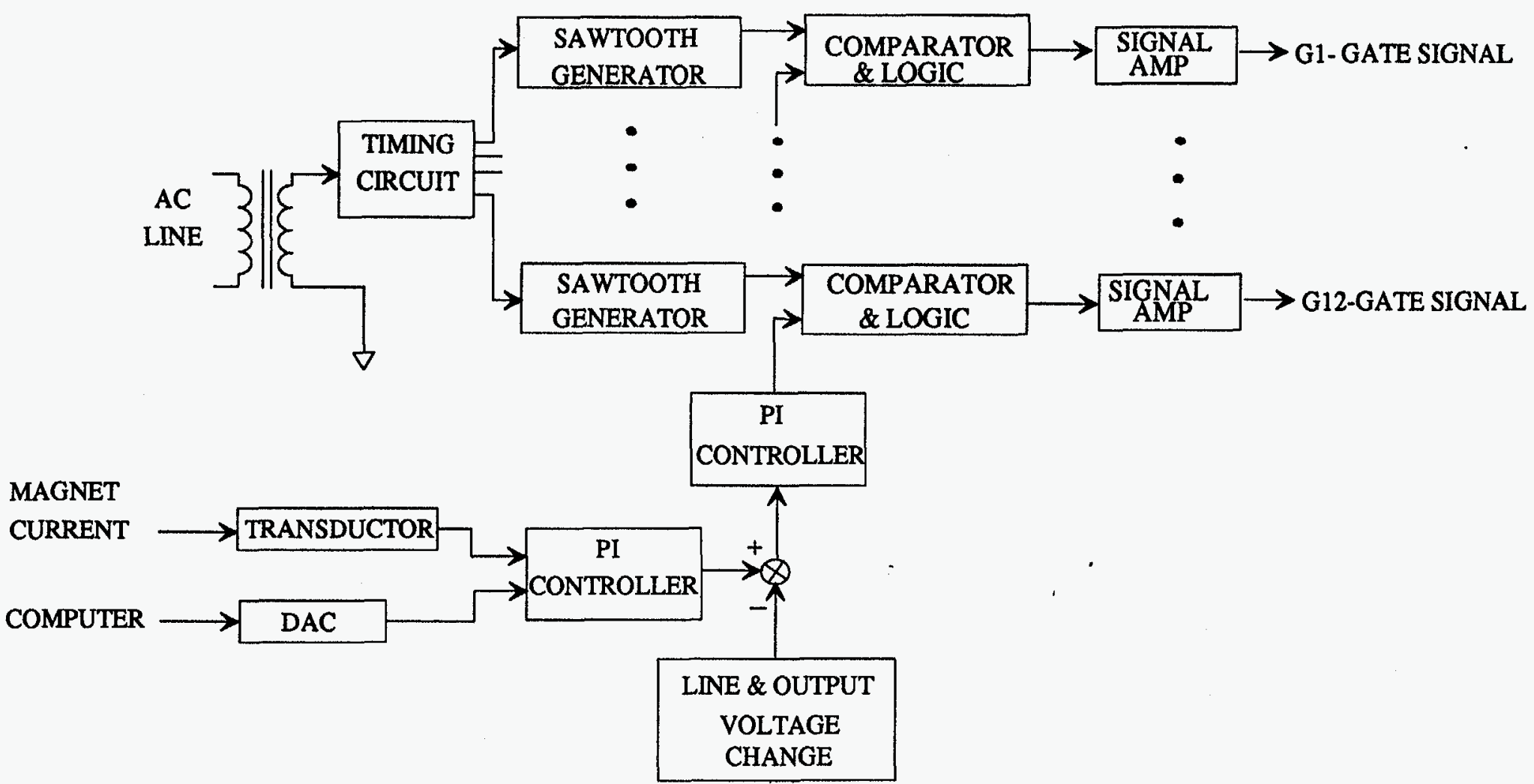

Figure 6. Triggering Circuit Block Diagram 


\subsection{Calculation of Power Supply Rating}

The voltage, power rating and cooling water required for the power supply are calculated in the following.

\subsubsection{Voltage and Power Rating}

For a magnet chain consisting of 8 magnets in series, the voltage drop can be calculated as follows:

$$
\mathrm{V}=\mathrm{RI}
$$

where $R=0.09 \Omega$, thus:

$$
\begin{aligned}
& \mathrm{V}=0.09 \times 420=37.8 . \mathrm{V} \\
& \mathrm{V}_{\mathrm{t}}=8 \times 37.8 \times 1.1^{*}=332.64 \mathrm{~V} \text {, we assume } 335 \mathrm{~V} \text { rating. } \\
& \mathrm{P}_{\max }=335 \times 420=141 \mathrm{~kW} \\
& \mathrm{P}_{\text {rated }}=141 \mathrm{~kW}
\end{aligned}
$$$$
\text { and for } 8 \text { magnets: }
$$

Maximum Power:

Rated Power:

* In the above calculation the cable voltage drop is assumed to be $10 \%$.

The average output voltage of each three-phase half wave-converter is given by [3]:

$$
\mathrm{V}_{\mathrm{dc}}=3 \mathrm{~V}_{\mathrm{m}} \frac{\sqrt{3}}{2 \pi} \cos \alpha
$$

The rms value of the output voltage is given by:

$$
\mathrm{V}_{\mathrm{rms}}=\sqrt{3} \mathrm{~V}_{\mathrm{m}}\left(\frac{1}{6}+\frac{\sqrt{3}}{2 \pi} \cos 2 \alpha\right)^{1 / 2}
$$

The output voltage harmonic is calculated as follows:

$$
\mathrm{V}_{\mathrm{h}}=3 \mathrm{~V}_{\mathrm{m}} \frac{\sqrt{3}}{2 \pi} \sum_{\mathrm{p}=1}^{\infty}(-1)^{\mathrm{p}_{1}}\left\{\frac{\cos \left(3 \mathrm{p} \omega_{0} t+(3 \mathrm{p}+1) \alpha\right)}{(3 \mathrm{p}+1)}-\frac{\cos \left(3 \mathrm{p} \omega_{0} t+(3 \mathrm{p}-1) \alpha\right)}{(3 \mathrm{p}-1)}\right\}
$$

where $V_{m}$ is the peak voltage value of the ac source, $\alpha$ is the firing angle of the converter, $p$ is the harmonic order and $\omega_{0}$ is the fundamental frequency of the converter.

The input power factor is defined as: 


$$
\mathrm{PF}=\frac{\mathrm{V}_{\mathrm{ms}} \mathrm{I}_{1}}{\mathrm{~V}_{\mathrm{ms}} \mathrm{I}_{\mathrm{ms}}} \cos (\phi)
$$

where $I_{1}$ is the fundamental rms component of the input current, and $\phi$ is the displacement angle between the fundamental components of the input current and voltage. In a three-phase halfwave converter, the average dc output voltage will be reduced due to the voltage drop in the converter transformer. Thus the output dc voltage of the converter is calculated as:

$$
V_{d}=3 V_{m} \frac{\sqrt{3}}{2 \pi} \cos \alpha-\frac{3 \omega L_{s}}{2 \pi} I_{d}
$$

where $L_{s}$ is the per-phase transformer inductance and $I_{d}$ is the dc output current of the power supply.

\subsubsection{Cooling Water Requirement}

One gallon of water per minute can cool $1 \mathrm{~kW}$ power dissipation with a $6.8^{\circ} \mathrm{F}$ temperature rise. For solid state devices we design for a $14^{\circ} \mathrm{F}\left(7.8^{\circ} \mathrm{C}\right)$ temperature rise. Since a $75 \mathrm{~A}$ current at 60 degree conduction angle passes through each thyristor with a $2.5 \mathrm{~V}$ voltage drop, then the total power loss for 12 thyristors will be $2.25 \mathrm{~kW}$. This power loss requires $2.25 \times 6.8 / 14=1.1$ gpm cooling water to provide only $14^{\circ} \mathrm{F}$ of temperature rise.

For buses and transformers a temperature rise of $30^{\circ} \mathrm{F}\left(16.6^{\circ} \mathrm{C}\right)$ is assumed. We assumed that no more than $15 \%$ of total power $(21.2 \mathrm{~kW})$ represents the losses through the buses and transformers, with $80 \%$ of those losses cooled via water and the other $20 \%$ of power losses cooled through convection cooling. Therefore, for a $30^{\circ} \mathrm{F}$ temperature rise, the amount of cooling water needed is calculated to be: $21.2 \times 0.8 \times 6.8 / 30=3.85 \mathrm{gpm}$. Thus the total amount of cooling water needed for 1 dipole power supply is $1.1+3.85=4.95 \mathrm{gpm}$. For the rating of this power supply $5 \mathrm{gpm}$ cooling water is specified.

\subsection{Interlocks}

In order to operate the power supply safely and protect it against faults and overloading, the following interlocks are needed.

1) Faults: Any fault such as line to line, line to ground, and short circuit of the output power will be detected and consequently the power supply will be turned off. 
If any of the following takes place the power supply shall trip off.

2) Low water flow

3) Over temperature water

4) Transformer and choke over temperature

5) Thyristors over temperature

6) AC line current imbalance and ac over current (an indication of excessive ac input current)

7) Over current to ground (an indication of excessive flow of current to ground)

8) DC over current

9) Door open.

The following parameters will be monitored continuously:

1) AC line voltage

2) AC line current

3) DC output voltage

4) DC output current

5) Power supply cabinet temperature.

6) Return water temperature

The following signals will be inputs to the power supply:

1) Interlock Reset

2) Power ON

3) Power OFF

4) Count up/ count down signals.

\subsection{Modelling, Computer Simulation and Analysis of Results}

In order to simulate the power supply operation, a model was used. For power transformers and interphase transformers, inductance, resistance and mutual inductance were considered. The filter choke was modelled with an inductance in series with its resistance. For filter capacitors, their equivalent series resistances were taken into account to calculate the power losses in the filter capacitors. The magnet load was modelled as eight separate dipole magnets connected in series. Each dipole magnet model consists of an inductance in series with its resistance and a capacitance to account for the capacitance between the magnet and ground. Figure 7 shows the model which was used for the dipole magnets. In the presented model $\mathbf{R}_{m}$ and $L_{m}$ are dipole magnet resistance and inductance respectively. $C_{g}$ represents the magnet 
capacitance with respect to ground. Pspice computer software was used to simulate the behavior of the PAR dipole power supply. In our studies the following assumptions were made:

a) The impedance of the ac source connected to the power supply was assumed to be $5 \%$. This information was needed to study the voltage drop at the transformer terminals.

b) $20 \%$ imbalance of ac source voltage was considered to evaluate the effect of interphasing transformers.

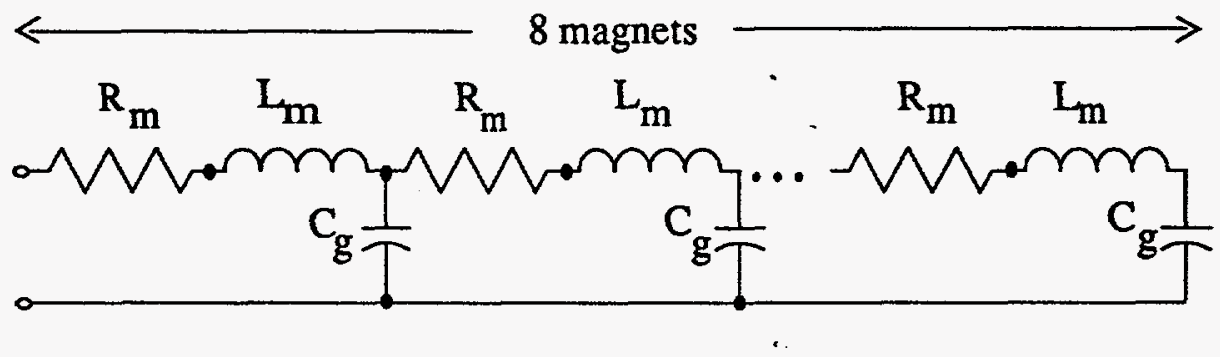

Figure-7 Dipole Magnet Model for Simulation

The study of PAR dipole power supply consists of three parts as follows:

1) The rated input voltage of the power supply was applied to the power supply and the current in the magnet was measured. The ripple content, current regulation, and circuit response to a step change were then evaluated.

2) The effect of harmonic currents injected from the power supply to the utility line is investigated.

3) Input kVA, efficiency and power factor for the power supply were computed.

Part -1 The results which were obtained from the computer simulation of the power supply indicated that the controller can regulate the current within the specified limit. The current regulation and current ripple were then measured. Figure 8 shows the power supply current response to a step change of $420.0 \mathrm{~A}$. The output current can follow a step change of $420.0 \mathrm{~A}$ in less than one second. The value of the ripple from the plot in Figure 8 is calculated as $\Delta \mathrm{I} / \mathrm{I}_{\max }= \pm 2.4 \mathrm{~mA} / 420 \mathrm{~A}$, thus: $\Delta \mathrm{I} / \mathrm{I}_{\max }= \pm 5.7 \times 10^{-6}$. The desired value is $\pm 3 \times 10^{-4}$. The calculated value of the ripple is much smaller than what was expected. This low value of ripple 
is due to the large amount of inductance in the load, ideal capacitor in the integrator, and ideal amplifiers in the regulator.

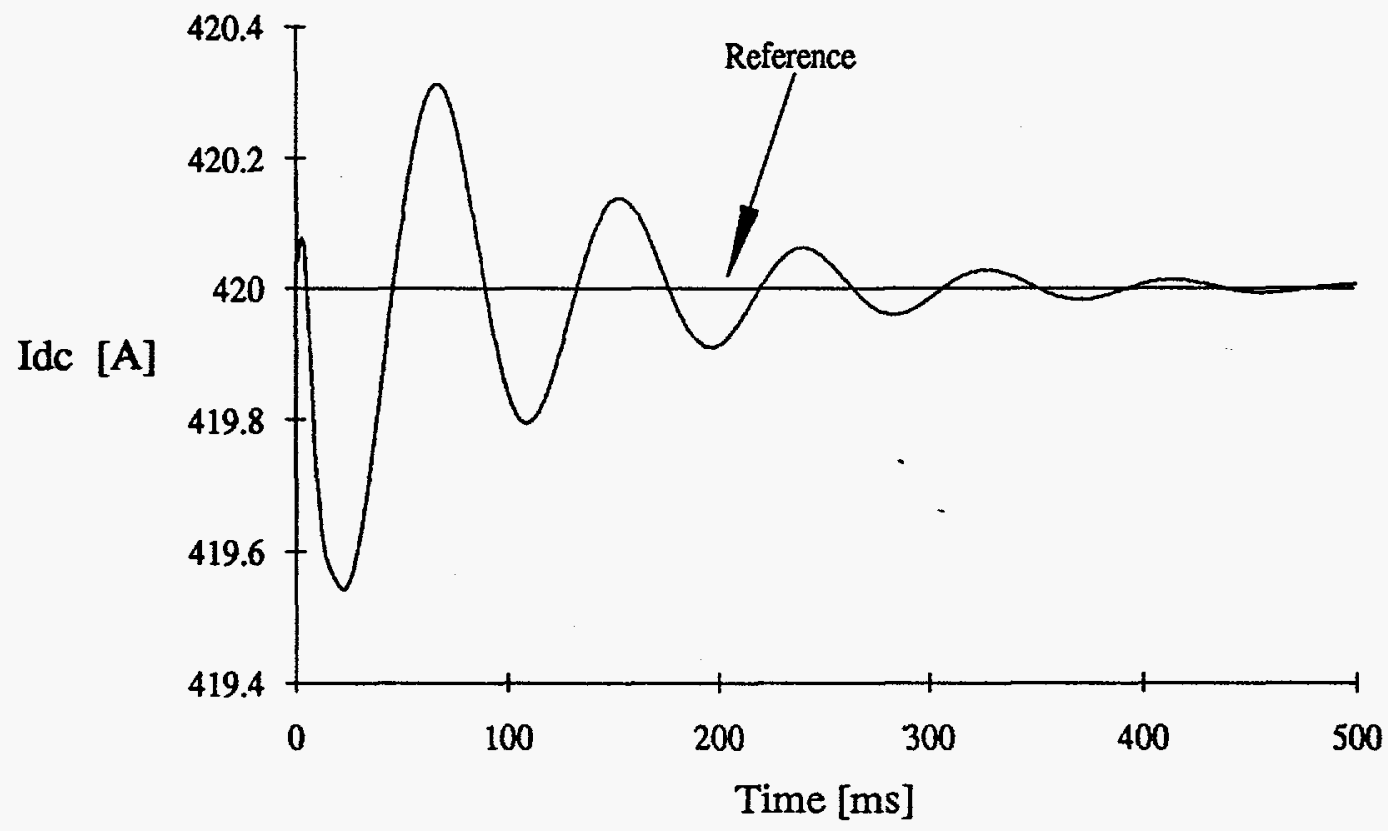

Figure-8 Power Supply Current Response to a 420.0 A Step

Part-2 The harmonic contents of the input current can be calculated by the following equation [4]:

$$
i_{2}=\frac{6}{N \pi} I_{d}\left[\cos \omega t-\frac{1}{11} \cos 11 \omega t+\frac{1}{13} \cos 13 \omega t . . .\right]
$$

where $I_{d}$ is the dc current in the magnet, $N$ is the transformer turn ratio and $i_{a}$ is the transformer input current. The above equation indicates that the line current has harmonics of the order of $\mathrm{h}=12 \mathrm{k} \pm 1$, where $\mathrm{k}$ is an integer with values of $\mathrm{k}=1,2, \ldots$. The harmonic currents injected into the utility system by the power supply can be eliminated by the addition of a filter to the input of the power supply. However, the filter design must take into account the ac system impedance at harmonic frequencies, in order to provide adequate filtering and to avoid certain resonance conditions. The system impedance depends on the system configuration, loads, generation pattern, and transmission line in service. Therefore, any change in the system configuration will require the modification of the filter. However, the harmonic contents of the current have a minimal effect on a stiff system. Transmission lines with low impedance and large substation transformer can provide a stiff system.

Part-3 The input kVA, efficiency and power factor for the power supply were computed at the rated load current. These parameters are tabulated in Table-1. 
Table-1

\begin{tabular}{|l|c|}
\hline \hline Input kVA & 184 \\
\hline Power Factor & 0.91 \\
\hline Efficiency & 0.90 \\
\hline
\end{tabular}

The power supply efficiency accounts for power losses in transformers, chokes, capacitor bank, diodes and thyristors.

\subsection{Conclusion}

A twelve-pulse, wye group, power supply was simulated to investigate the behavior of the power section, power filter, and control loops. Based on our study the following conclusions can be drawn:

1) Due to the nature of the load which contains a large amount of inductance, a relatively small power filter was needed to suppress the output current ripple:

2) Both voltage and current loops utilized proportional plus integral controllers to regulate the current in the magnet.

3) The power supply injects current harmonics into the utility system whose order is given by $\mathrm{h}=12 \mathrm{k} \pm 1$, where $\mathrm{k}$ is an integer. In order to eliminate the injected harmonic currents, a tuned filter at certain frequency must be designed. However, the design of such a filter relies on the system impedance. The system impedance changes with any modification in the system configuration. Therefore, a tuned filter can operate properly as long as the system configuration remains unchanged. In other words, any changes in the system configuration can disturb the correct operation of the tuned filter. It was concluded that a properly sized substation transformer can minimize the effect of harmonic current on the utility system and a filter will not be used.

4) The output current of the power supply can follow a 420.0 A step change and reach the steady state level in less than one second.

5) The power supply efficiency is about $90 \%$ and its power factor is a little more than $91 \%$ at full load current. 


\section{References:}

[1] Advanced Photon Source Design Handbook Vol. II, Dec. 1989.

[2] W.F. Preag,"A high-current low-pass filter for magnet power supplies.", IEEE Trans. Industrial Electronics and Control Instrumentation, Vol IECI-17, Number 1, Feb. 1970, pp.1622.

[3] M. H. Rashid, Power Electronics, Circuits, Devices, and Applications. John Wiley \& Sons, Inc., New York 1988.

[4] N. Mohan, T. M. Undeland, and W.P. Robbins, Power Electronics Converters, Applications, and Design. John Wiley \& Sons, Inc., New York 1989. 